\title{
Message from the Dean
}

W e at the Indiana University School of Social Work are very pleased to present this second issue of Advances in Social Work. In publishing Advances in Social Work, we envision a journal that provides an opportunity for faculty, practitioners, students, and other professionals to have a forum whereby scholarly work related to social work research, education, and practice can be published. Advances in Social Work, as the title connotes, serves to contribute to the knowledge base of the social work profession by providing a publication that advances knowledge and demonstrates effectiveness and quality improvements for social work through research, education, and practice.

The Indiana University School of Social Work has a very distinguished history. Founded in 1911, it is the oldest social work program in the nation continuously affiliated with a university. Next year we will be celebrating our 90th anniversary, commemorating many milestones in teaching, research, and service. This year we celebrated the 25th anniversary of the BSW Program. The publication of Advances in Social Work marks another milestone in the history of the School of Social Work. It advances our mission by disseminating new knowledge for the advancement of the profession.

I am grateful to a number of individuals who have contributed extensively to make Advances in Social Work possible. My gratitude is extended to Dean Roberta Greene and Interim Dean Sheldon Siegel for supporting the development and publication of the journal, and to Dr. Paul Sachdev, the first editor, whose vision gave birth to the journal. A special thank you goes to Dr. Barry R. Cournoyer, who now serves as Editor. His leadership, attention to detail, and quest for quality are clearly evident. The Editorial Board, whose names appear inside the front cover, deserve special credit for their direction, support, and hard work. Finally, the Consulting Editors, whose names also can be found inside of the front cover, have served as reviewers for the manuscripts submitted. Their able assistance is greatly appreciated.

In closing I feel compelled, as the new Dean, to make a few personal comments about the Indiana University School of Social Work. The School has approximately 900 students and offers the BSW, MSW, and Ph.D. degrees. The School offers educational programs on five Indiana University campuses, located in Bloomington, Gary, Indianapolis, South Bend, and Richmond. The School of Social Work has a rich history of providing quality social work education, producing excellent research and scholarship, and having a strong commitment to serving the profession and the people of Indiana. Headquartered in the state capital, Indianapolis, the School has strong ties to state agencies and engages in a variety of projects in collaboration with these agencies. The University and the School of Social Work serve as models for utilizing advanced technology in the management of its programs. Advances in Social Work represents another significant contribution that the School is making. With such a strong history, quality faculty, and strong support, it is a privilege to be at such a high quality school of social work.

Michael A. Patchner, Ph.D.

Dean

Fall 2000 